\title{
Computational fluid dynamics study of pull and plug flow boundary condition on nasal airflow
}

\begin{abstract}
The recent advances in the computer based computational fluid dynamics (CFD) software tools in the study of airflow behavior in the nasal cavity have opened an entirely new field of medical research. This numerical modeling method has provided both engineers and medical specialists with a clearer understanding of the physics associated with the flow in the complicated nasal domain. The outcome of any CFD investigation depends on the appropriateness of the boundary conditions applied. Most researchers have employed plug boundary condition as against the pull flow which closely resembles the physiological phenomenon associated with the breathing mechanism. A comparative study on the effect of using the plug and pull flow boundary conditions are evaluated and their effect on the nasal flow are studied. Discretization error estimation using Richardson's extrapolation (RE) method has also been carried out. The study is based on the numerical model obtained from computed tomographic data of a healthy Malaysian subject. A steady state Reynold averaged Navier-Stokes and continuity equations is solved for inspiratory flow having flow rate 20 $\mathrm{L} / \mathrm{min}$ representing turbulent boundary conditions. Comparative study is made between the pull and plug flow model. Variation in flow patterns and flow features such as resistance, pressure and velocity are presented. At the nasal valve, the resistance for plug flow is 0.664 $\mathrm{Pa}-\mathrm{min} / \mathrm{L}$ and for pull flow the value is $0.304 \mathrm{~Pa}-\mathrm{min} / \mathrm{L}$. The maximum velocity at the nasal valve is $3.28 \mathrm{~m} / \mathrm{s}$ for plug flow and $3.57 \mathrm{~m} / \mathrm{s}$ for pull flow model.
\end{abstract}

Keyword: CFD; Nasal resistance; Plug flow; Pull flow; Grid convergence index 